\title{
Dynamic Analysis of Impact Model of Slipping Tramcar Prevention Equipment Based on an Energy Absorber
}

\author{
Guiyun Xu, Shuo Hu, Xiaoguang Zhang, Jiazhou Zhu, Huipeng Zheng, and Hongxin Wang
}

School of Mechatronic Engineering, China University of Mining and Technology, Xuzhou 221116, China

Correspondence should be addressed to Shuo Hu; liulicumt@sina.com

Received 4 September 2015; Accepted 17 December 2015

Academic Editor: Mario Terzo

Copyright (C) 2016 Guiyun Xu et al. This is an open access article distributed under the Creative Commons Attribution License, which permits unrestricted use, distribution, and reproduction in any medium, provided the original work is properly cited.

\begin{abstract}
The protection equipment of slipping tramcar in inclined shaft is the important safety equipment to ensure safety production in mine transportation and equipment. The Slipping Tramcar Prevention Equipment is mainly composed of an intercepting door and a buffering system, in which an energy absorber is the key component. The braking dynamic model of the energy absorber is studied by establishing a Lagrange equation and simulating the braking progress by the software of Simulink. The braking simulation distances curves of the energy absorber are obtained under the different initial conditions of tramcar mass and velocity, which shows that the tramcar velocity and mass both have a significant influence on the braking distance. The analysis on variance and range is developed for further comparison on the two key factors implying that tramcar mass is of the most great importance. Moreover, a braking distance formula is built based on the analysis results. On the other hand, field experiments are conducted in Qishan Mine, and experiment results show that the maximum error between the braking distance formula value and the experiment value is $11.98 \%$, and the minimum error is $2.72 \%$. The experimental results are consistent with the theoretical results.
\end{abstract}

\section{Introduction}

The inclined shaft transportation is one of the most important parts in production and transportation in coal mine, used for conveying workers, coal, and mining tools. The multitramcar transportation is the key method in the inclined shaft transportation, and the accidents caused by the tramcars in the inclined shaft often occur, during the coal mine production, approximately accounting for $22.1 \%$ in mine accidents, bringing a serious influence on safety of production and progress of shaft construction $[1,2]$. So the research on the structure and braking abilities of the slipping tramcar Prevention equipment is of great importance to the protection for the safety of production in the inclined shaft of the coal mine and will provide a theoretical guidance and methodology for the optimal design of the slipping tramcar Prevention equipment [3-5].

A number of researchers all over the world have made a great number of studies on the slipping tramcar Prevention equipment. Wen-Hai developed a nonlinear model of collision between the flexible intercepting door and the tramcar, analyzed the vibration characteristics of the tracks, using a vibration coupling model of the track and tramcar, and presented the best installation position of the limiting device to control the vibration of the track which is in the middle of the track [6-8]. Ling et al. established a three-dimensional dynamic analysis model of the tramcar in high speed to study problems of the tramcar's derailment in detail. In particular, the derailment status and track deformation were analyzed [9]. Zhang and Wu established a simulation model of the transportation of the inclined shaft based on mathematical statistics and field test, and the analysis results were applied to make an improvement on existing transportation system [10]. Johnston et al. put forward a step by step energy absorber device and carried out a field test to identify the performance characteristics and dynamic response of the equipment [11]. The mining institute of the UK obtained some geometry optimization parameters of the track through the analysis on track transportation accidents and considered that the improved orbit parameters can be helpful to effectively avoid track derailment accidents [12] and carried out a field test on the slipping prevent equipment, based on a step by step energy absorber, with the National Institute for coal mining of the Administration of the UK [13]. Belforte et al. and 


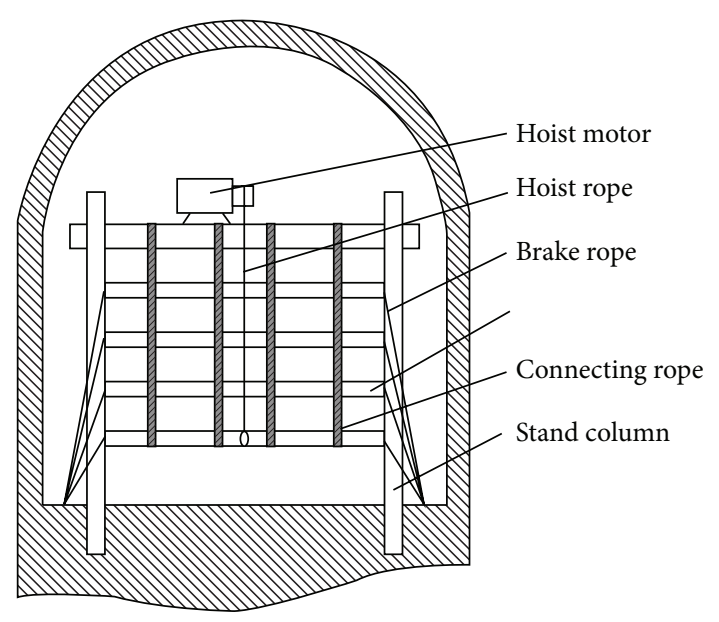

FIgURE 1: The intercepting door structure schematic drawing tramcar-hindering barrier.

their team established a numerical dynamic model of track to analyze the working performance, including the track's horizontal and vertical dynamic characteristics. The analysis on instantaneous state vectors of tramcar and track in interaction with each other has been conducted through a numerical simulation software $[14,15]$. However, few researches conducted on braking characteristics of the slipping prevent device and its braking performance, especially on the sectors on braking distance. A series of braking curves in different initial conditions are presented, and the comparison between the field test and simulation demonstrates the efficiency of the dynamic model of the slipping prevent device in this paper. The braking characteristics of the energy absorber are studied theoretically and experimentally to guide the design optimization of the slipping prevent device.

\section{The Structure and Working Principle of the Slipping Tramcar Prevention Equipment}

The slipping tramcar Prevention equipment is composed of an intercepting door and a buffering system. The intercepting door includes the intercepting curtain and support framework, as shown in Figure 1. The support framework looks like a door frame, including two stand columns fixed on both sides of the track symmetrically, in the inclined shaft. In particular, a hoist motor is fixed on the steel beam of the support framework. The flexible and compound intercepting curtain are composed of four wire ropes and four steel pipes. And the wire ropes are connected crossly with the steel pipes by soldering. In addition, the intercepting curtain is connected with the buffering system with the braking ropes. When a slipping tramcar accident occurs, the intercepting door has an direct impact on the slipping tramcar, protecting the tramcar body and delivering the shock energy to the buffering system. The hoist motor fixed the steel beam of the support framework is made to hoist the intercepting curtain, like a roller shutter.

The buffering system plays a major role in absorbing kinetic energy caused by slipping tramcar. And the energy

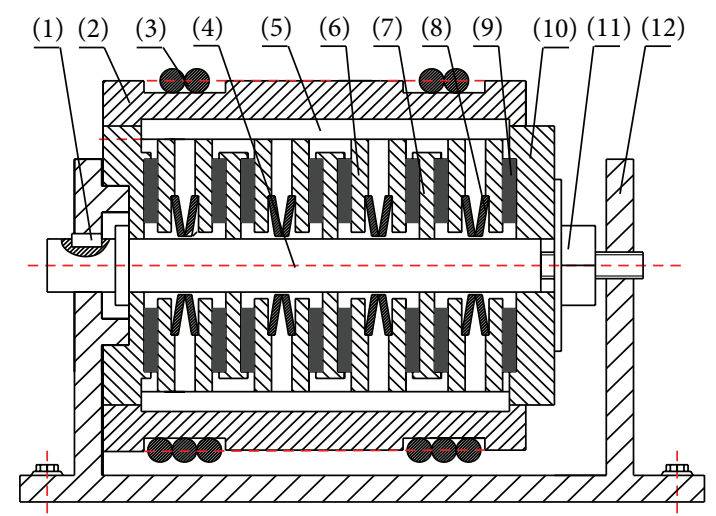
(1) Locating key
(7) Internal brake disc
(2) Roller
(8) Disc spring
(3) Braking rope
(9) Friction plate
(4) Principal axis
(10) Side brake disc
(5) Connecting key
(11) Adjusting nut
(6) External brake disc
(12) Support pedestal

FIGURE 2: Structure sketch of multidisc energy absorber.

absorber as shown in Figure 2, consuming the shock energy through the close-packed friction plates, is the key component of the buffering system containing two energy absorbers. The support pedestal of the energy absorber is fixed on the roadway of the inclined shaft with foundation bolts. Generally speaking, the problems, including friction discs' abrasion, temperature's rising sharply, and pressure's instability, can be improved effectively by configuring more disc springs and friction plates in the energy absorber. Normally, the braking rope is preloaded by the adjusting nut, to absorb the temporary impact energy, reducing the injury on the energy absorber and improving safety performance.

Normally, when the tramcar is coming, the hoist motor will hoist the intercepting curtain. After the tramcar passing completely, the hoist motor drops the intercepting curtain down through the hoisting wire rope. However, when in accident, the tramcar happens to slip down the track, and the hoist motor cannot hoist the intercepting curtain to prevent the slipping tramcar in time. Meanwhile, the intercepting door slows the slipping tramcar down to stop it through the braking rope rolled on the energy absorber because the braking rope rotates the roller to make the friction plates rub each other.

\section{Braking Dynamic Model of Energy Absorber}

3.1. Force Analysis of Energy Absorber. A braking dynamic model of the braking progress was developed for the energy absorber, according to the primary analysis on the slipping tramcar Prevention equipment shown in Figure 3. Obviously, for easier analysis in this dynamic model, the energy absorber can be simplified as a braking force, $F$. Similarly, a preload force $f_{1}$ is put to weaken the vibration caused by temporary shock from the slipping tramcar. In the model, the slipping tramcar is also controlled by the friction $f_{2}$ caused by the 


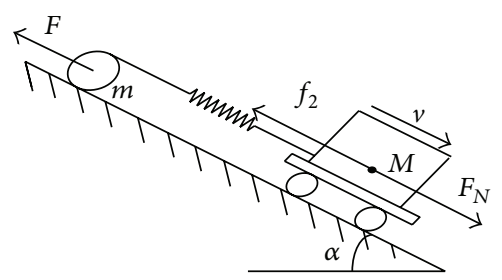

FIGURE 3: Braking dynamic model of energy absorber.

track and the force $F_{N}$ down the inclined shaft exhibited in Figure 3.

According to the dynamic model depicted in Figure 3, in the braking progress, the braking work can be simplified as

$$
W=F l,
$$

where $F=2 f_{1}+F_{N}$. In particular, $F_{N}$ is a pulling force of the braking rope from the intercepting door, when slipping tramcar accidents occur.

Accordingly, the Lagrange motivation function of the tramcar is given as

$$
\frac{d}{d t}\left(\frac{\partial L}{\partial \dot{y}}\right)-\frac{\partial L}{\partial y_{i}}=Q_{i},
$$

where $y_{i}$ is the generalized coordinates, $L=T-U$ the Lagrangian function, $Q_{i}$ the generalized force in the generalized coordinates, and $T$ and $U$ the kinetic function and potential function. Figure 4 shows the displacement change of the braking wire in the braking progress, and Figure 4(a) shows the initial condition of the braking progress; $l$ is the length of the braking wire between the tramcar and the energy absorber. Figure 4(b) shows the distance change of the braking wire compared with the initial condition, and $y_{1}$ is the displacement of the tramcar and $y_{2}$ is the displacement of tangent point of the braking wire on the roller of the energy absorber in the braking progress. Under this circumstance, the kinetic energy of the whole braking system is expressed as

$$
\begin{aligned}
T & =T_{1}+T_{2}+T_{3} \\
& =\frac{1}{4} m r^{2} \dot{\varphi}^{2}+\frac{1}{2} M \dot{y}_{1}^{2}+\frac{1}{6} \rho l\left(\dot{y}_{1}^{2}+r \dot{y}_{1} \dot{\varphi}+r^{2} \dot{\varphi}^{2}\right),
\end{aligned}
$$

where $T_{1}$ is the kinetic energy of the energy absorber, $T_{2}$ the kinetic energy of the slipping tramcar, and $T_{3}$ the kinetic energy of the braking rope. The potential energy can be expressed as

$$
\begin{aligned}
U= & \frac{1}{2} k\left(y_{1}-r \varphi\right)^{2}-M g y_{1} \sin \alpha \\
& -\frac{1}{2} \rho l\left(y_{1}+r \varphi\right) g \sin \alpha,
\end{aligned}
$$

where $k$ is the elastic coefficient of the braking rope, $y_{1}$ the displacement of the tramcar, $r$ the radius of the roller of the energy absorber, $\varphi$ the angular displacement of the energy absorber, $\rho$ the linear density of the braking rope, and $l$ is the initial length.
According to the principle of virtual work, in the generalized coordinates, the generalized forces are expressed as

$$
\begin{aligned}
& Q_{1}=\frac{\left[\sum w\right]}{\delta y_{1}}=-f_{2}, \\
& Q_{2}=\frac{\left[\sum w\right]}{\delta \varphi}=-F r,
\end{aligned}
$$

where $\left[\sum w\right]$ is the elementary work, and $f_{2}$ the friction on the slipping tramcar from the track. Accordingly, in the braking progress, it is supposed that the length change of the braking is linear, and $y_{1}$ is the displacement of the tramcar, and $y_{2}$ the line displacement of the roller of the energy absorber. Under this circumstance, the dynamical equation of the buffering system is given as

$$
[M]\{\ddot{y}\}+[k]\{y\}=\{Q\},
$$

where $\{\ddot{y}\}$ is the acceleration vector, $\{y\}$ displacement vector, $\{Q\}$ the exciting force vector, $[M]$ the mass matrix, and $[k]$ the stiffness matrix. Based on the real symmetry of $[M]$ and $[k]$, it is concluded that the feature vectors of the function (6) are orthogonal vectors. Therefore, $[u]$ is supposed as the mode matrix of function (6), and the matrix of the function can be expressed as

$$
\{y\}=[u]\{p\}
$$

where $\{p\}$ is another generalized coordinates matrix. Accordingly, the dynamic equation of the buffering system is further transformed as follows:

$$
\begin{aligned}
& \ddot{p}_{1}=-\frac{k_{11}^{\prime}}{m_{11}} p_{1}+u_{11} \frac{Q_{1}}{m_{11}^{\prime}}+u_{21} \frac{Q_{2}}{m_{11}^{\prime}}, \\
& \ddot{p}_{2}=-\frac{k_{22}^{\prime}}{m_{22}} p_{1}+u_{12} \frac{Q_{1}}{m_{22}^{\prime}}+u_{22} \frac{Q_{2}}{m_{22}^{\prime}} .
\end{aligned}
$$

3.2. Braking Dynamic Simulation of Energy Absorber. Figure 5 shows the braking dynamics simulation model of the energy absorber based on the functions (6) and (7) in which Fsum and Novelocity both are the input signals. Fsum represents the force of the braking rope, and Novelocity is a binary signal. When the velocity of the tramcar exceeds 0 , signal Novelocity will present 1. Stuck is the output signal of state flow, and the logical control module of the simulation system. Two exclusive-OR gates represent the locking and slipping states of the tramcar. When the simulation system is in static, a blank signal, the default, will be input into state flow. When the external force exerted on the tramcar exceeds the friction force from the track, the signal Stuck will be activated instantly.

\section{Working Condition Simulation of Energy Absorber and Test Verification}

Given the complex working conditions and the various simulation modes of the slipping tramcar Prevention equipment, 


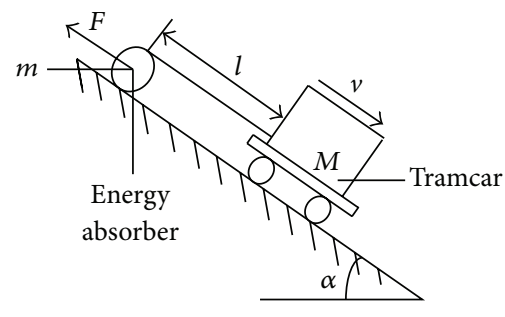

(a) Initial condition

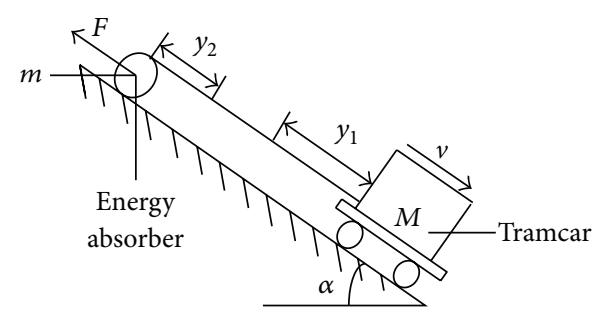

(b) Braking progress

FIGURE 4: Displacement of braking wire.

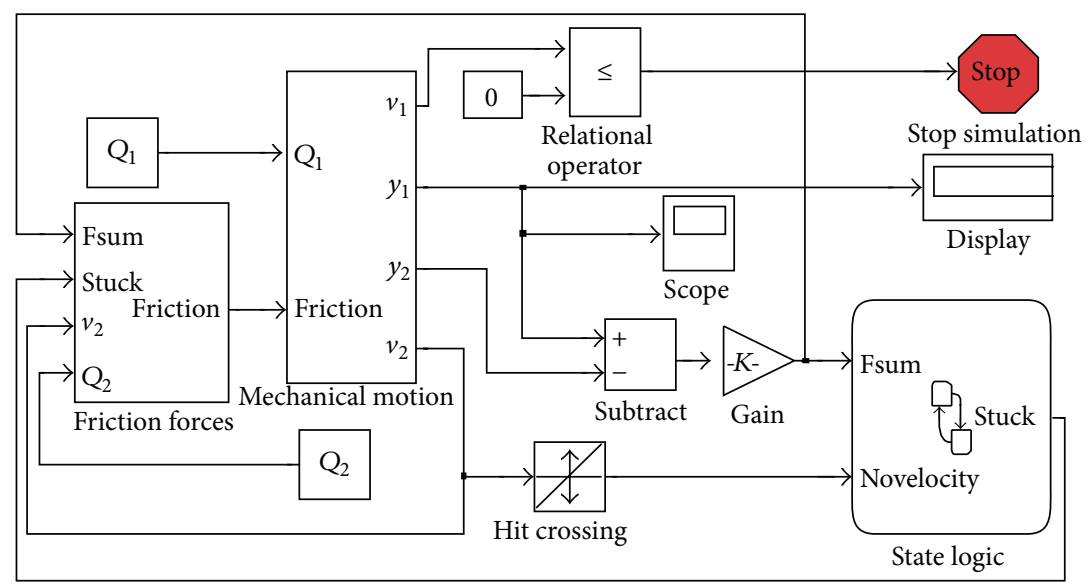

FIGURE 5: Braking dynamic simulation model of energy absorber.

more accurate and comprehensive working parameters must be taken into account seriously, directly affecting the accuracy of output and the validity of the subsequent analysis and field test.

4.1. Working Condition Simulation of Energy Absorber. This simulation model of the system is presented in Figure 5. According to "the Coal Industrial Standard MT933-2005" and the actual working conditions, in order to improve the dynamic and static performance of loading of the braking system, the technical parameters of the tramcar and the energy absorber are shown in Table 1.

Figures 6(a)-6(e) show the braking distance change curves of tramcars of $1000 \mathrm{~kg}, 2000 \mathrm{~kg}, 3000 \mathrm{~kg}, 4000 \mathrm{~kg}$, and $5000 \mathrm{~kg}$, respectively. In consideration of the comparative analysis on the key characteristics on the braking distance in the buffering system, tramcar braking distance change curves of different velocities and different mass are shown in Figures 7 and 8, respectively. It can be easily be concluded that the tendency of the braking distances and the slopes of tramcar braking distance change curves increase gradually as the velocity of the slipping tramcar of same mass. On the other hand, the tendency of the braking distance increases linearly gradually as the mass of the slipping tramcar in the same velocity, as shown in Figure 8.

4.2. Results and Analysis of Braking Distance. After comprehensive analysis of Figures 5, 6, and 7, it is clear that both
TABLE 1: The technical parameters of the tramcar and energy absorber.

\begin{tabular}{|c|c|}
\hline Basic physics & Parameter values \\
\hline Single tramcar weight, $\mathrm{kg}$ & 600 \\
\hline Load weight, $\mathrm{kg}$ & 1200 \\
\hline Wheel diameter, mm & 300 \\
\hline Arm of rolling friction force, $\mathrm{mm}$ & 0.7 \\
\hline Initial length of the braking rope, $\mathrm{m}$ & 5 \\
\hline Number of the braking rope & 2 \\
\hline Braking rope diameter, $\mathrm{mm}$ & 20 \\
\hline Braking rope linear density, $\mathrm{kg} / \mathrm{m}$ & 1.38 \\
\hline The elastic modulus of the braking rope, $\mathrm{N} / \mathrm{m}^{2}$ & $1.0 \times 10^{11}$ \\
\hline The mass of the energy absorber, $\mathrm{kg}$ & 80 \\
\hline Radius of the roller of the energy absorber, $\mathrm{m}$ & 0.2 \\
\hline Single energy absorber's braking force, $\mathrm{kN}$ & 65 \\
\hline Angle of the inclined shaft, ${ }^{\circ}$ & 15 \\
\hline
\end{tabular}

of velocity and mass are of great importance to the braking distance of the slipping tramcar. So the work that remains to be done is to analyze and study the variance of the influence of velocity and mass on the braking distance, according to the data of Table 3 extracted from Figure 6. In particular, the factors of Table 3 are presented in Table 2. Table 4 shows the variance analysis of tramcar braking distance. Obviously, it can be seen that the sum of squares of deviations, mean square 

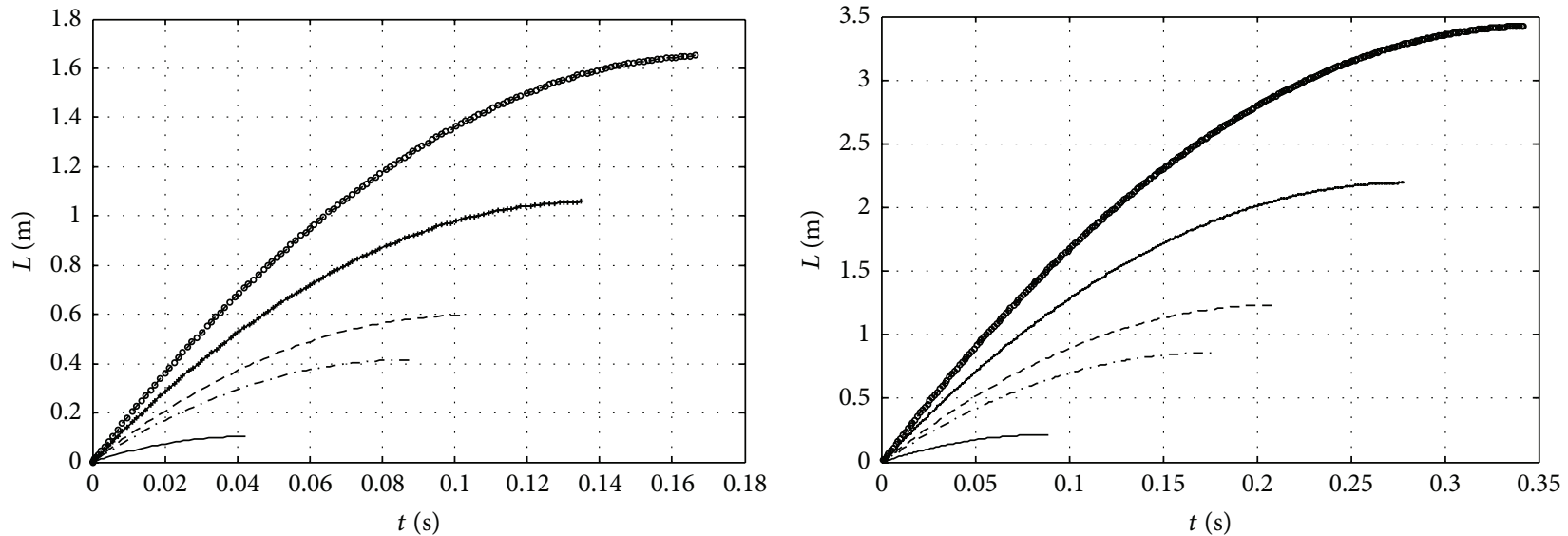

$$
\begin{aligned}
-v & =5 \mathrm{~m} / \mathrm{s} \\
-.-v & =10 \mathrm{~m} / \mathrm{s} \\
--v & =12 \mathrm{~m} / \mathrm{s}
\end{aligned}
$$

$$
\longrightarrow v=16 \mathrm{~m} / \mathrm{s}
$$$$
\text { - } v=20 \mathrm{~m} / \mathrm{s}
$$

(a)

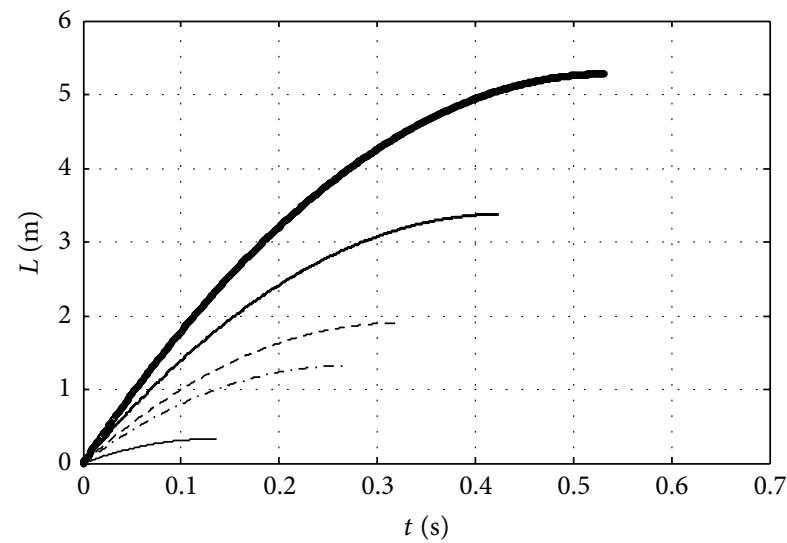

$\begin{aligned}-v & =5 \mathrm{~m} / \mathrm{s} \\ -\quad v & =10 \mathrm{~m} / \mathrm{s}\end{aligned}$ $--v=12 \mathrm{~m} / \mathrm{s}$

$$
\begin{aligned}
\longrightarrow v & =16 \mathrm{~m} / \mathrm{s} \\
\hdashline-v & =20 \mathrm{~m} / \mathrm{s}
\end{aligned}
$$

(c)

$$
\begin{aligned}
-v & =5 \mathrm{~m} / \mathrm{s} \\
--v & =10 \mathrm{~m} / \mathrm{s} \\
--v & =12 \mathrm{~m} / \mathrm{s}
\end{aligned}
$$

(b)

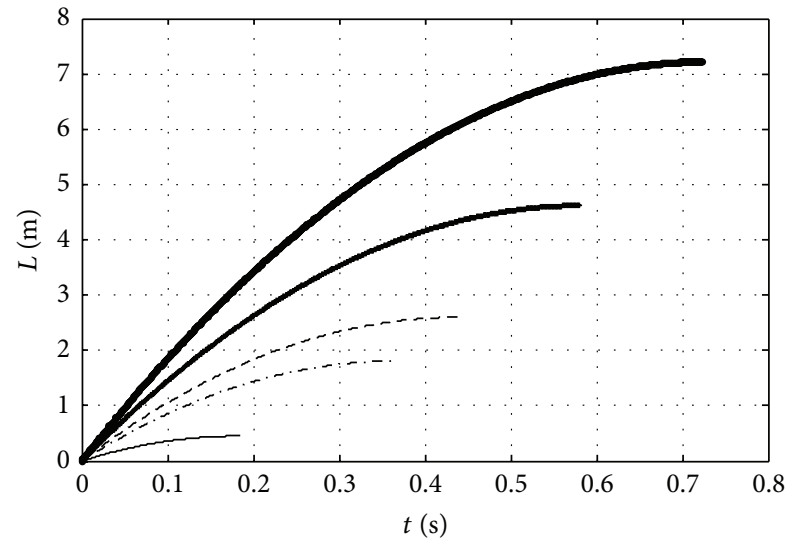

$\begin{aligned}-v & =5 \mathrm{~m} / \mathrm{s} \\ -.-v & =10 \mathrm{~m} / \mathrm{s} \\ --v & =12 \mathrm{~m} / \mathrm{s}\end{aligned}$

$\rightarrow v=16 \mathrm{~m} / \mathrm{s}$

- $v=20 \mathrm{~m} / \mathrm{s}$

(d)

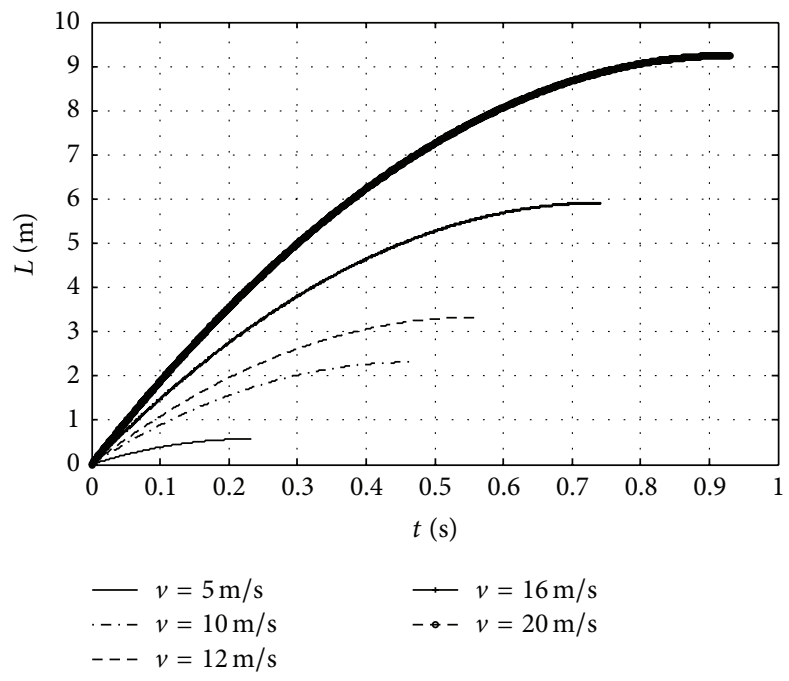

(e)

FIGURE 6: Braking distance change curves of tramcar. 


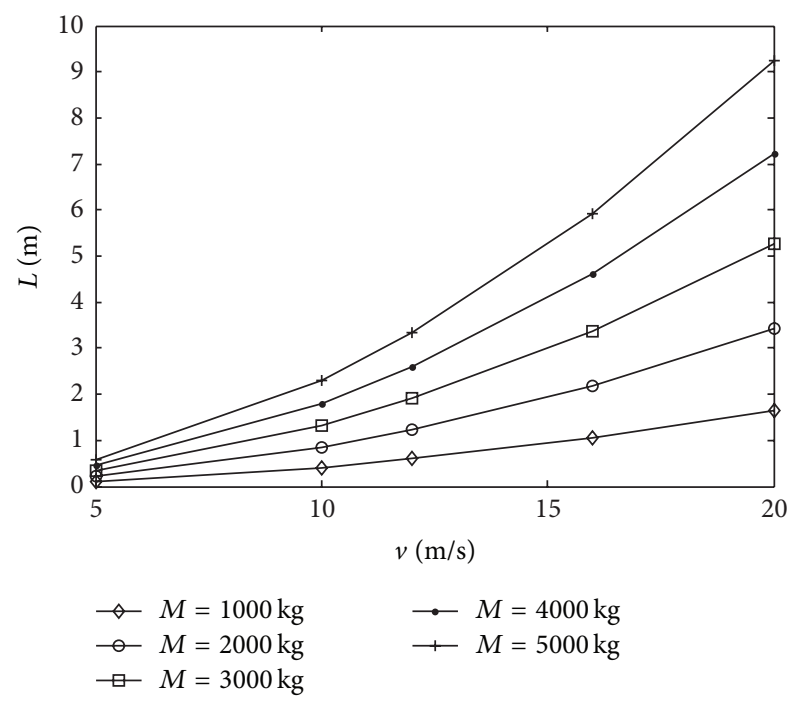

FIGURE 7: Tramcar braking distance change curves of different velocity.

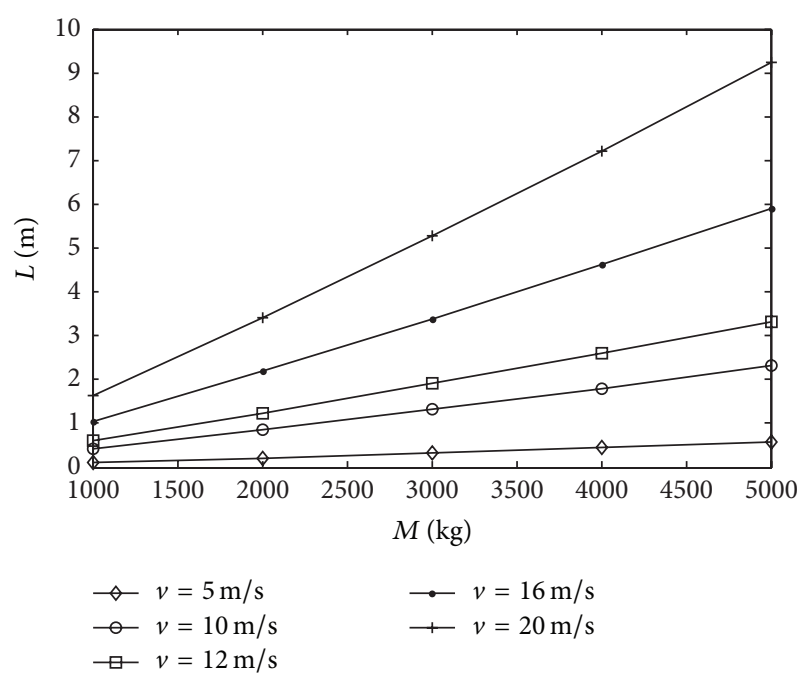

FIGURE 8: Tramcar braking distance change curves of different mass.

deviation, and the value of the factor $A$, tramcar mass, are $77.07,19.27$, and 15.95 , respectively. And the sum of squares of deviations, mean square deviation, and the value of the factor $B$, tramcar velocity, are $38.53,9.6$, and 7.98, respectively. After the comparative analysis on the data above, it is easily concluded that factor $A$ is twice as factor $B$ on the braking distance, not obviously demonstrating the differences of two factors in the way of variance. Accordingly, more detailed analysis on mass and velocity range of tramcar remains to be done. Table 5 shows the mass and velocity range analysis of the tramcar in the braking system. It is clear that the analysis result implies that $R_{A}$ is 5.02 and $R_{B}, 3.52$. Namely, the range of the mass of the tramcar is much more than the range of the velocity. Hence, a conclusion can be conducted that the factor $A$, namely the tramcar mass, has a more significant influence than the factor $B$, the tramcar velocity. So, although
TABLE 2: Factors and levels of tramcar.

\begin{tabular}{lccccc}
\hline Factor & 1 & 2 & 3 & 4 & 5 \\
\hline Mass, kg & 1000 & 2000 & 3000 & 4000 & 5000 \\
Velocity, m/s & 5 & 10 & 15 & 20 & 25 \\
\hline
\end{tabular}

the dynamic model of braking system is complicated, the tramcar is still the most important vector in the braking progress of the slipping tramcar. Therefore, an equation of the braking distance was developed as

$$
L=a \times M^{\beta} \times v^{\gamma},
$$

where $a, \beta, \gamma$ are equal to $2.6051 \times 10^{-6}, 1.067$, and 1.9978 , respectively, based on the analysis of the data in Tables 2, 3, 4, and 5 . Hence, the terminal equation of the braking distance based on mass and velocity is expressed as

$$
L=2.0651 \times 10^{-6} \times M^{1.067} \times v^{1.9978} .
$$

In particular, the relation of slipping distance $L$ and tramcar velocity $v$ can be expressed as

$$
v=\sqrt{2 g L(\sin \alpha)-k \cos \alpha+v_{0}^{2}},
$$

where $v_{0}$ is the initial velocity of the tramcar, $k$ is the force arm of the roller friction on the tramcar, and $\alpha$ is the angle of the inclined shaft. Accordingly, (10) can also be presented accurately as

$$
\begin{aligned}
L= & 2.6051 \times 10^{-6} \times M^{1.067} \\
& \cdot\left(\sqrt{2 g L\left(\sin \alpha-\frac{k \cos \alpha}{r}\right)}+v_{0}^{2}\right)^{1.9978} .
\end{aligned}
$$

Table 6 shows the comprehensive comparison between the output values of braking distance equation (10), assigned from Table 3, and the simulation results. It is clear that the maximum error and the minimum error are $0.96 \%$ and $0.02 \%$, respectively.

4.3. Braking Distance Experiment Analysis of Energy Absorber. An experimental system as shown in Figure 9 was established in Qishan Mine of Xuzhou mining group, to test the safety performance and the analysis results above. Accordingly, the experiment test on the buffering system was conducted as shown in Figure 10, according to "the Coal Industrial Standard MT933-2005" and the experiment parameters shown in Table 7.

4.3.1. No-Load Running Test of Tramcar. According to the way adopted in "the Coal Industrial Standard MT933-2005", the tramcar in a resting state in the inclined shaft broke away from the hoist rope and started to slip down the track, because of the gravity. The slipping tramcar Prevention equipment got activated, when the velocity came to the minimum of the activation velocity. The equation of length of the inclined shaft 
TABLE 3: Simulation results of tramcar braking distance.

\begin{tabular}{|c|c|c|c|c|c|c|c|}
\hline Serial number & Factor 1 & Factor 2 & $\begin{array}{c}\text { Simulation value of } \\
\text { braking distance, } \\
\mathrm{m}\end{array}$ & Serial number & Factor 1 & Factor 2 & $\begin{array}{c}\text { Simulation value of } \\
\text { braking distance, } \\
\mathrm{m}\end{array}$ \\
\hline 1 & 1 & 1 & 0.1041 & 14 & 3 & 4 & 3.378 \\
\hline 2 & 1 & 2 & 0.4139 & 15 & 3 & 5 & 5.279 \\
\hline 3 & 1 & 3 & 0.5957 & 16 & 4 & 1 & 0.4516 \\
\hline 4 & 1 & 4 & 1.058 & 17 & 4 & 2 & 1.804 \\
\hline 5 & 1 & 5 & 1.651 & 18 & 4 & 3 & 2.598 \\
\hline 6 & 2 & 1 & 0.2147 & 19 & 4 & 4 & 4.619 \\
\hline 7 & 2 & 2 & 0.8571 & 20 & 4 & 5 & 7.216 \\
\hline 8 & 2 & 3 & 1.234 & 21 & 5 & 1 & 0.5783 \\
\hline 9 & 2 & 4 & 2.193 & 22 & 5 & 2 & 2.311 \\
\hline 10 & 2 & 5 & 3.424 & 23 & 5 & 3 & 3.328 \\
\hline 11 & 3 & 1 & 0.3304 & 24 & 5 & 4 & 5.916 \\
\hline 12 & 3 & 2 & 1.32 & 25 & 5 & 5 & 9.244 \\
\hline 13 & 3 & 3 & 1.901 & & & & \\
\hline
\end{tabular}

TABLE 4: Variance analysis of tramcar braking distance.

\begin{tabular}{lccccc}
\hline Sources of variation & Sum of squares of deviations & Degree of freedom & Mean square deviation & $F$ & Conspicuousness \\
\hline Tramcar mass $A$ & 77.07 & 4 & 19.27 & 15.95 & Highly obvious \\
Tramcar velocity $B$ & 38.53 & 4 & 9.6 & 7.98 & Highly obvious \\
Error range & 19.32 & 16 & 1.2 & \\
Sum & 134.92 & 24 & & \\
\hline
\end{tabular}

TABLE 5: Mass and velocity range analysis of tramcar.

\begin{tabular}{lccc}
\hline Tramcar mass & Parameter & Tramcar velocity & Parameter \\
\hline TA1 & 1.68 & TB1 & 3.82 \\
TA2 & 6.71 & TB2 & 7.92 \\
TA3 & 9.66 & TB3 & 12.21 \\
TA4 & 17.16 & TB4 & 16.69 \\
TA5 & 26.81 & TB5 & 21.38 \\
KA1 & 0.34 & KB1 & 0.76 \\
KA2 & 1.34 & KB2 & 1.58 \\
KA3 & 1.93 & KB3 & 2.44 \\
KA4 & 3.43 & KB4 & 3.34 \\
KA5 & 5.36 & KB5 & 4.28 \\
RA & 5.02 & RB & 3.52 \\
\hline
\end{tabular}

and the minimum of the activation velocity can be expressed as

$$
L=\frac{v^{2}}{2 g(\sin \alpha-\omega \cos \alpha)},
$$

where $L$ and $\alpha$ are the length and angle of the inclined shaft, respectively, and $v$ and $\omega$ are the minimum of the activation velocity and travelling resistance coefficients of the tramcar, respectively.

Full-Load Running Test of Tramcar. The full-load tramcar was weighed and the error range is within $\pm 5 \%$. The relation

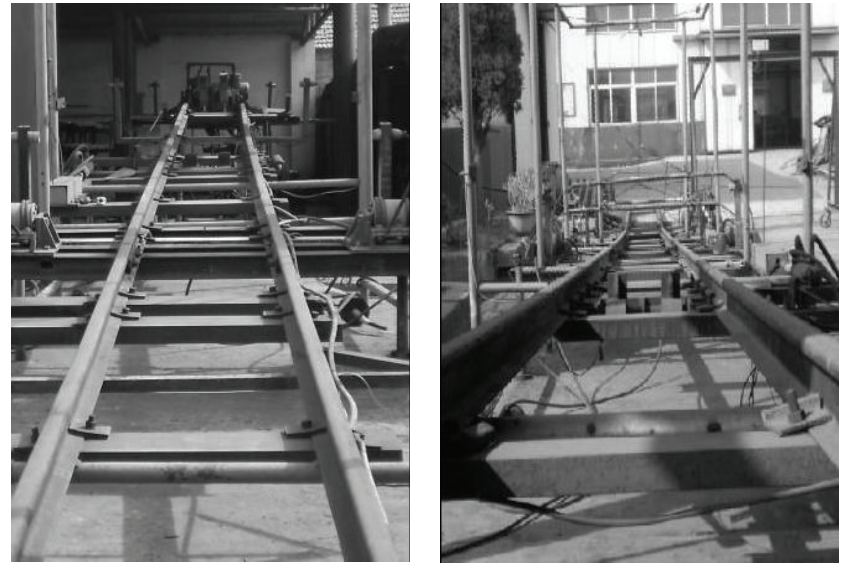

FIGURE 9: Experiment field of tramcar slipped protection equipment.

equation of the kinetic energy of the tramcar and length of the inclined shaft is given as

$$
L=\frac{E}{M g(\sin \alpha-\omega \cos \alpha)},
$$

where $L$ and $\alpha$ are the length and angle of the inclined shaft, respectively, and $E$ and $\omega$ are the kinetic energy and traveling resistance coefficients of the tramcar, respectively.

Measurement of the Braking Length. The braking length of the slipping tramcar, to some extent, is approximately equal to the 


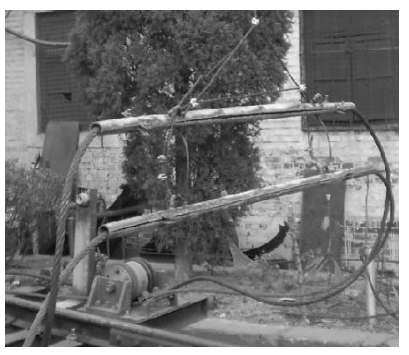

(a)

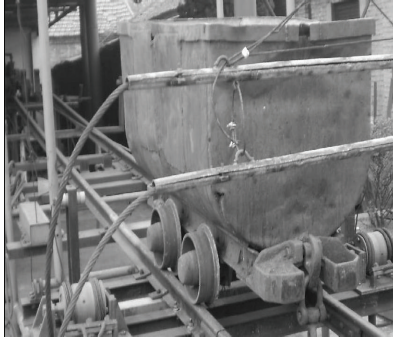

(b)

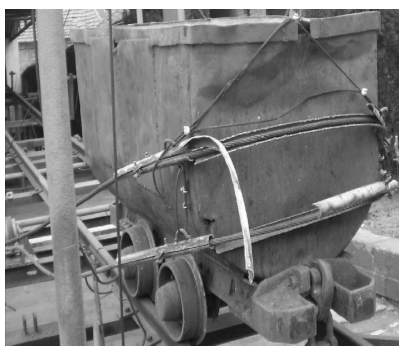

(c)

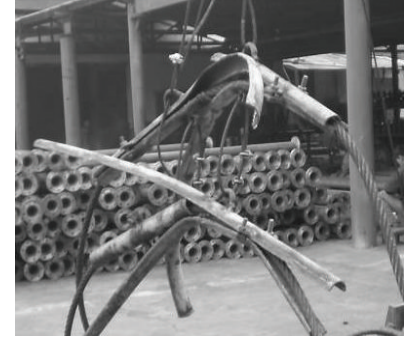

(d)

FIGURE 10: Collision process practicality photo of tramcar-hindering barrier.

TABLE 6: Error analysis of tramcar braking distance.

\begin{tabular}{|c|c|c|c|c|c|c|c|}
\hline $\begin{array}{l}\text { Serial } \\
\text { number }\end{array}$ & $\begin{array}{l}\text { Simulation } \\
\text { value of } \\
\text { braking } \\
\text { distance, } \mathrm{m}\end{array}$ & $\begin{array}{c}\text { Equation } \\
\text { value of } \\
\text { braking } \\
\text { distance, } \mathrm{m}\end{array}$ & Error, \% & $\begin{array}{c}\text { Serial } \\
\text { number }\end{array}$ & $\begin{array}{l}\text { Simulation } \\
\text { value of } \\
\text { braking } \\
\text { distance, } \mathrm{m}\end{array}$ & $\begin{array}{c}\text { Equation } \\
\text { value of } \\
\text { braking } \\
\text { distance, } \mathrm{m}\end{array}$ & Error, \% \\
\hline 1 & 0.1041 & 0.1031 & 0.96 & 14 & 3.378 & 3.4001 & -0.65 \\
\hline 2 & 0.4139 & 0.4117 & 0.53 & 15 & 5.279 & 5.31 & -0.59 \\
\hline 3 & 0.5957 & 0.5926 & 0.52 & 16 & 0.4516 & 0.4525 & -0.20 \\
\hline 4 & 1.058 & 1.0529 & 0.48 & 17 & 1.804 & 1.8072 & -0.18 \\
\hline 5 & 1.651 & 1.6444 & 0.40 & 18 & 2.598 & 2.6014 & -0.13 \\
\hline 6 & 0.2147 & 0.216 & -0.61 & 19 & 4.619 & 4.6217 & -0.06 \\
\hline 7 & 0.8571 & 0.8626 & -0.64 & 20 & 7.216 & 7.2177 & -0.02 \\
\hline 8 & 1.234 & 1.2416 & -0.62 & 21 & 0.5783 & 0.5742 & 0.71 \\
\hline 9 & 2.193 & 2.206 & -0.59 & 22 & 2.311 & 2.2931 & 0.77 \\
\hline 10 & 3.424 & 3.4451 & -0.62 & 23 & 3.328 & 3.3007 & 0.82 \\
\hline 11 & 0.3304 & 0.3329 & -0.76 & 24 & 5.916 & 5.8641 & 0.88 \\
\hline 12 & 1.32 & 1.3295 & -0.72 & 25 & 9.244 & 9.1581 & 0.93 \\
\hline 13 & 1.901 & 1.9138 & -0.67 & & & & \\
\hline
\end{tabular}

TABLE 7: Parameters of tramcar and energy absorber.

\begin{tabular}{|c|c|c|c|}
\hline Physical quantity & Parameter value & Physical quantity & Parameter value \\
\hline Tramcar self-weight, kg & 600 & Rope linear density, kg/m & 1.38 \\
\hline Single tramcar load, kg & 1200 & The elastic modulus of the braking rope, $\mathrm{N} / \mathrm{m}^{2}$ & $1.0 \times 10^{11}$ \\
\hline Wheel diameter, mm & 300 & The mass of the energy absorber, $\mathrm{kg}$ & 80 \\
\hline Arm of rolling friction force, $\mathrm{mm}$ & 0.7 & Roller radius of the energy absorber, $\mathrm{m}$ & 0.2 \\
\hline Initial length of the braking rope, $\mathrm{m}$ & 5 & Braking force of the energy absorber, $\mathrm{kN}$ & 65 \\
\hline Number of the braking rope & 2 & Angle of the inclined shaft, ${ }^{\circ}$ & 15 \\
\hline Rope diameter, $\mathrm{mm}$ & 20 & & \\
\hline
\end{tabular}

TABLE 8: Factors and levels of tramcar.

\begin{tabular}{lccccc}
\hline Factor & 1 & 2 & 3 & 4 & 5 \\
\hline Mass, kg & 600 & 1000 & 1200 & 1500 & 1600 \\
Velocity, m/s & 5 & 8 & 10 & 12 & - \\
\hline
\end{tabular}

pulled length of the braking rope. So, the braking length can be measured by the rolled angle of the roller of the energy absorber. And the results of the measurement of the braking length are shown in Table 9. And the factors of the slipping tramcar are shown in Table 8, and “-” implies that the data in the blank was not collected.

4.3.2. Data Analysis and Processing of Braking Distance. In comprehensive analysis of the measured length of the experimental test and simulation, it is clear that the results of the experimental test and simulation have significant differences as shown in Figure 11, to some extent. On the other hand, the processing results in Table 10 show that the maximum and minimum error between the experimental result and the theoretical calculating value are $11.98 \%$ and 
TABLE 9: Experiment data of tramcar braking distance.

\begin{tabular}{|c|c|c|c|c|c|c|}
\hline Times & Mass factor & Velocity factor & $\begin{array}{c}\text { Braking } \\
\text { distance of } \\
\text { left side, } m \\
\end{array}$ & $\begin{array}{c}\text { Braking } \\
\text { distance of } \\
\text { right side, } \mathrm{m}\end{array}$ & $\begin{array}{c}\text { Average rotational } \\
\text { circles of energy } \\
\text { absorber, } r\end{array}$ & $\begin{array}{c}\text { Experimental } \\
\text { braking } \\
\text { distance, } \mathrm{m} \\
\end{array}$ \\
\hline 1 & 1 & 1 & 0.057 & 0.056 & 0.045 & 0.0565 \\
\hline 2 & 1 & 2 & - & - & - & - \\
\hline 3 & 1 & 3 & - & - & - & - \\
\hline 4 & 1 & 4 & 0.346 & 0.323 & 0.266 & 0.334 \\
\hline 5 & 2 & 1 & 0.120 & 0.101 & 0.088 & 0.111 \\
\hline 6 & 2 & 2 & 0.301 & 0.191 & 0.196 & 0.246 \\
\hline 7 & 2 & 3 & 0.442 & 0.409 & 0.339 & 0.426 \\
\hline 8 & 2 & 4 & - & - & - & - \\
\hline 9 & 3 & 1 & 0.107 & 0.132 & 0.095 & 0.120 \\
\hline 10 & 3 & 2 & - & - & - & - \\
\hline 11 & 3 & 3 & 0.521 & 0.521 & 0.415 & 0.521 \\
\hline 12 & 3 & 4 & - & - & - & - \\
\hline 13 & 4 & 1 & 0.141 & 0.143 & 0.113 & 0.142 \\
\hline 14 & 4 & 2 & 0.352 & 0.376 & 0.29 & 0.364 \\
\hline 15 & 4 & 3 & - & - & - & - \\
\hline 16 & 4 & 4 & - & - & - & - \\
\hline 17 & 5 & 1 & 0.156 & 0.176 & 0.132 & 0.166 \\
\hline
\end{tabular}

TABLE 10: Experiment data processing of tramcar braking distance.

\begin{tabular}{lccc}
\hline Times of experiment & Experimental value of braking length, $\mathrm{m}$ & Theoretical value of braking length, $\mathrm{m}$ & Error range, \% \\
\hline 1 & 0.057 & 0.0598 & 5.84 \\
4 & 0.334 & 0.3436 & 2.84 \\
5 & 0.111 & 0.1031 & -6.7 \\
6 & 0.246 & 0.2636 & 7.11 \\
7 & 0.426 & 0.4117 & 3.29 \\
9 & 0.119 & 0.1252 & 4.95 \\
11 & 0.521 & 0.5002 & 4.03 \\
13 & 0.142 & 0.1589 & 11.98 \\
14 & 0.364 & 0.4064 & 11.59 \\
17 & 0.166 & 0.1702 & 2.72 \\
\hline
\end{tabular}

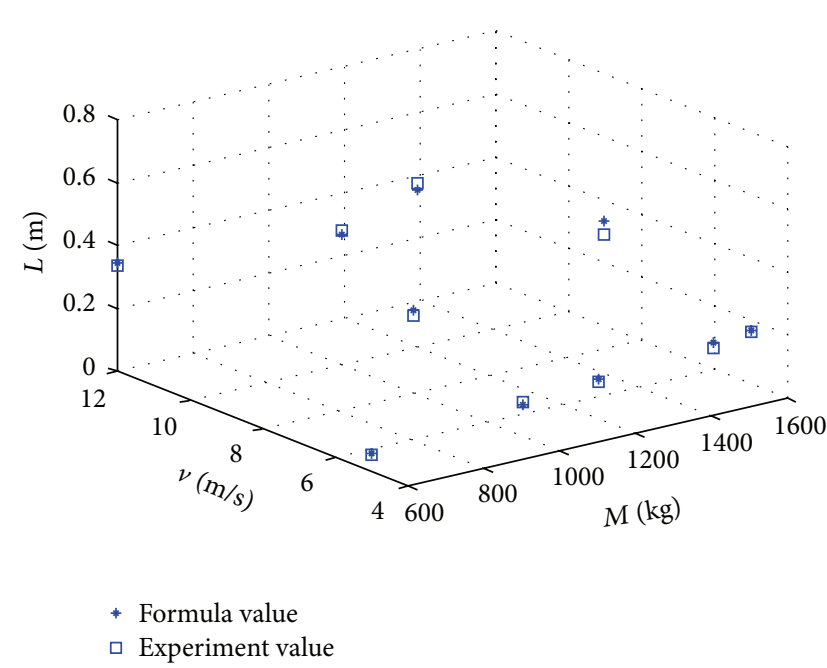

FIgURE 11: Experiment data of Tramcar braking distance.
$2.72 \%$, respectively. But the error is reasonable because of some contingency factors. Therefore, the models of the braking length and the energy absorber are valid.

\section{Conclusion}

Based on the actual working condition, a dynamic model of the energy absorber was established through the Lagrange equation. The braking characteristics of the protection equipment of slipping tramcar in inclined shaft are analyzed by Simulink, a dynamic analysis software. A conclusion was drawn that tramcar mass and velocity are the key factors on the braking length of the slipping tramcar, especially that the tramcar mass has a more significant influence on the braking result in the paper, according to the range values of the simulation and experimental data; namely, $R_{A}>R_{B}$, as shown in Table 5. Also, the models of the energy absorber and the equation of the braking distance were proved to 
be valid through comprehensive comparison analysis on the experimental test and theoretical calculation.

\section{Conflict of Interests}

The authors declare that there is no conflict of interests regarding the publication of this paper.

\section{Acknowledgments}

The authors are grateful to the anonymous referees for their valuable comments and suggestions for improving the presentation of this paper. The project is funded by the Priority Academic Program Development of Jiangsu Higher Education Institutions (PAPD).

\section{References}

[1] A. G. L. Pratt, "Mine haulage-options and the process of choice," in Tenth Underground Operators' Conference 2008, vol. 1 of Australasian Institute of Mining and Metallurgy Publication Series, pp. 179-187, Australasian Institute of Mining and Metallurgy, Melbourne, Australia, 2008.

[2] J. Eikhoff, "Developments in the German coal industry," Glueckauf Mining Reporter, no. 1, pp. 6-13, 2007.

[3] J.-H. Wang, X.-Z. Wang, and B.-J. Li, "Analysis and discussion on slipping tramcar prevent equipment of the inclined shaft," Coal Mine Modernization, no. 4, pp. 66-68, 2005.

[4] F. Heyns and J. Van Der Westhuizen, "A mining case study: the safe maintenance of underground railway track," Civil Engineering/Siviele Ingenieurswese, vol. 14, no. 5, pp. 8-10, 2006.

[5] F. J. Paus, "Latest developments in underground vehicle technology rubber tyred transportation in mines," Coal International, vol. 254, no. 6, pp. 16-18, 2006.

[6] H. E. Wen-Hai, Simulative Research on the Motion Character and Collision Course of Tramcar, The Library of Xian University of Science and Technology, Xi'an, China, 2004.

[7] W.-H. He, "Simulation analysis of impact between flexible bumper and tramcar," Hoisting and Conveying Machinery, vol. 4, pp. 60-64, 2009.

[8] W.-H. He, "Modeling and simulative analysis of dynamics characteristic of tramcar conveying system," Journal of System Simulation, vol. 20, no. 4, pp. 871-877, 2008.

[9] L. Ling, X.-B. Xiao, and X.-S. Jin, "Development of a simulation model for dynamic derailment analysis of high-speed trains," Acta Mechanica Sinica, vol. 30, no. 6, pp. 860-875, 2014.

[10] Z. Zhang and G. Wu, "Simulation of tramcar transportation systems in underground mine," Mining Research and Development, vol. 21, no. 2, pp. 27-31, 2001.

[11] A. G. Johnston, V. E. Taylor, and D. Waterhouse, "Towards transportation of men and materials," The Mining Engineer, no. 1, pp. 391-399, 1982.

[12] F. Heyns and J. Van Der Westhuizen, "A mining case study: the safe maintenance of underground railway track," Civil Engineering, vol. 14, no. 5, pp. 8-10, 2006.

[13] E. R. Bauer and C. J. Bise, "Ground control and worker safety in coal mines," Mining Engineering, no. 7, pp. 54-57, 2006.

[14] P. Belforte, F. Cheli, and R. Corradi, "Software for the numerical simulation of tramcar vehicle dynamics," International Journal of Heavy Vehicle Systems, vol. 10, no. 1-2, pp. 48-69, 2003.
[15] P. Belforte, F. Cheli, G. Diana, and S. Melzi, "Numerical and experimental approach for the evaluation of severe longitudinal dynamics of heavy freight trains," Vehicle System Dynamics, vol. 46, no. 1, pp. 937-955, 2008. 


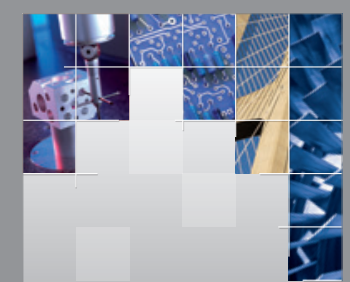

\section{Enfincering}
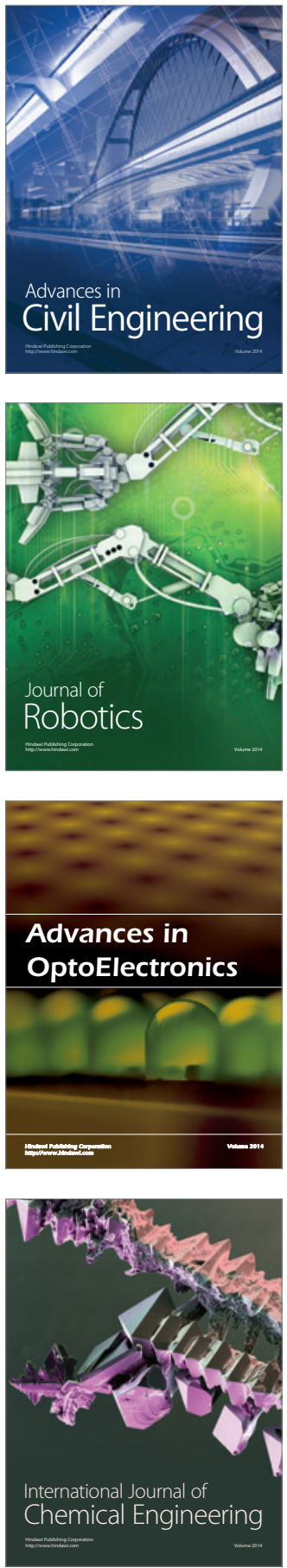

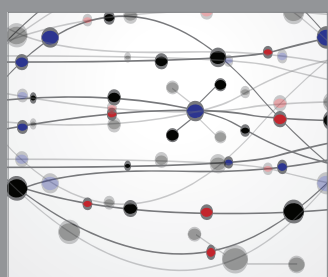

The Scientific World Journal

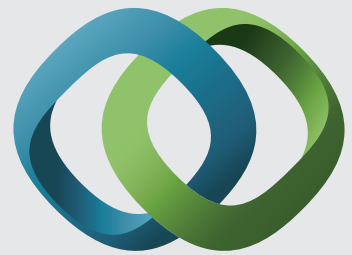

\section{Hindawi}

Submit your manuscripts at

http://www.hindawi.com
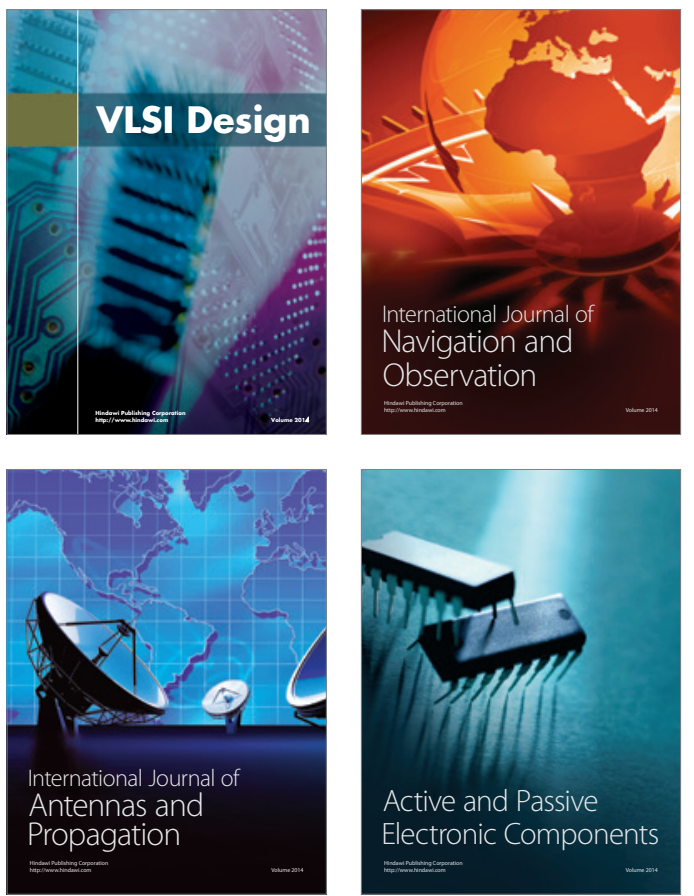
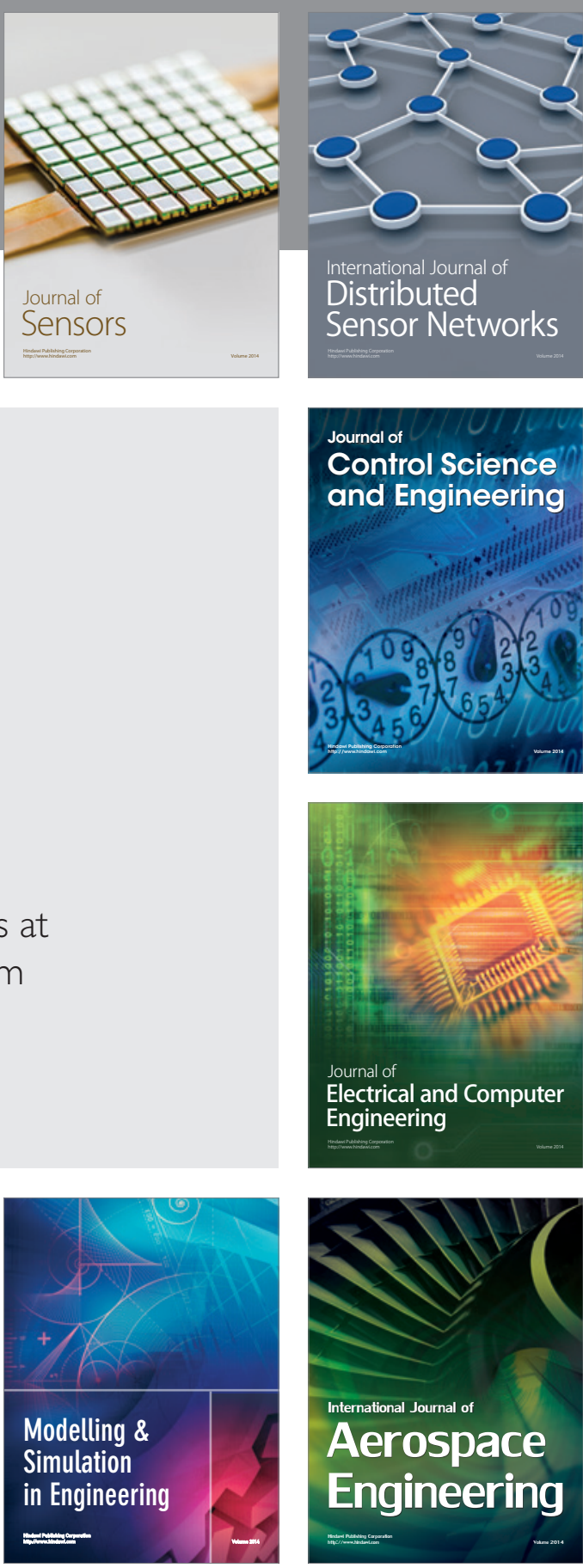

International Journal of

Distributed

Sensor Networks

Journal of

Control Science

and Engineering
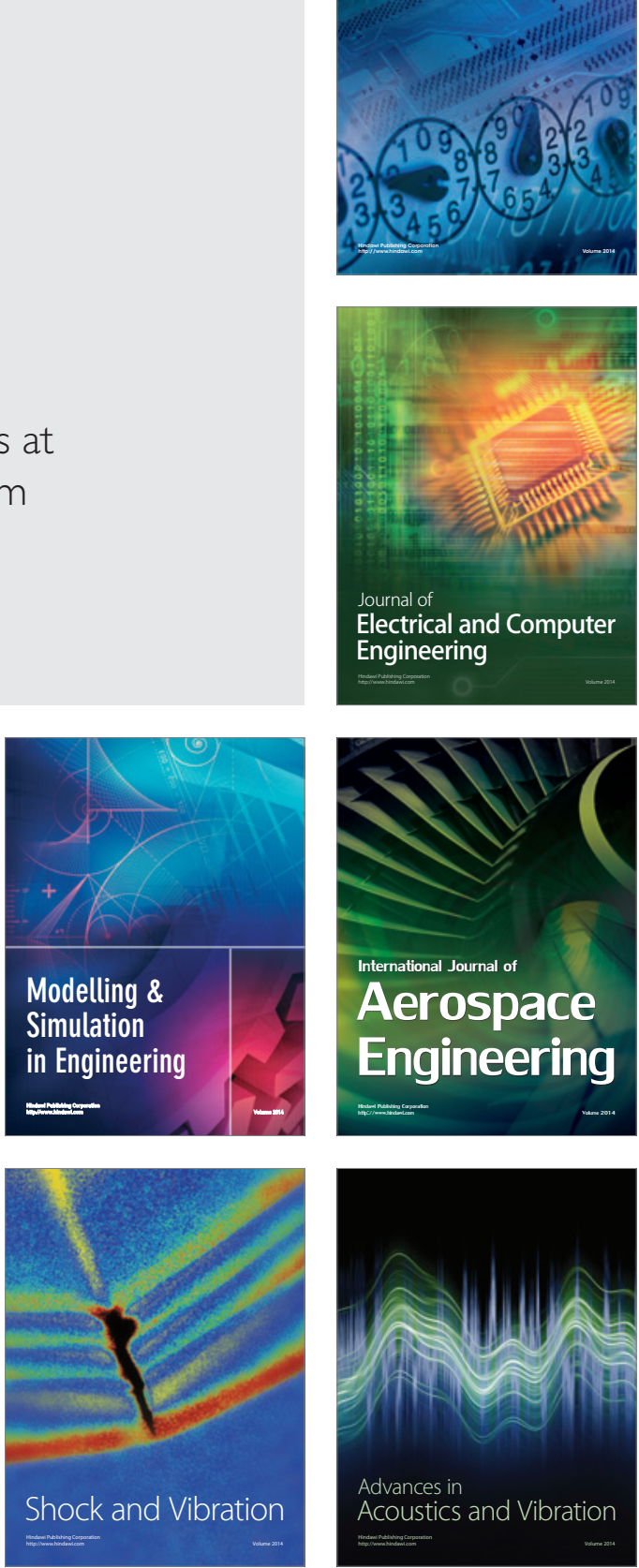